\title{
Rodas de pertencimento como proposta de formação de professores
}

\section{Conversation meetings: a proposal for teacher education}

\author{
Ida Leticia G. da Silva* \\ Maria do Carmo Galiazzi
}

\begin{abstract}
Resumo: Este trabalho refere-se a uma pesquisa de dissertação de mestrado do Programa de PósGraduação em Educação Ambiental da Universidade Federal do Rio Grande, na qual se buscou investigar o processo de constituição de uma professora, pesquisadora e educadora ambiental na prática docente. O argumento defendido refere-se ao potencial transformador da narrativa na construção do conhecimento sobre os processos vivenciados na formação de educadores, especialmente de professores iniciantes que enfrentam dilemas na sala de aula, bem como ao uso do diário como instrumento de refiguração da realidade do professor educador ambiental. Portanto, o diário em forma de narrativa precisa ser figurado, configurado e refigurado, articulado a processos de formação permanente em rodas de conversas, tendo como foco os dilemas enfrentados por professores em sala de aula, especialmente aqueles dos professores em inicio de carreira.
\end{abstract}

Palavras-chave: Educação Ambiental. Formação de Professores. Rodas de Conversa.

Abstract: This article refers to a research carried out as a requisite for the Post-Graduate Program in Environmental Education at the Federal University of Rio Grande. The aim of the study was to analyze the process of becoming a teacher, researcher and environmental educator. The thesis defended refers to the changing potential of narrative in the processes of knowledge construction in teacher education, in particular in initial education in which future teachers face problems in the classroom as well as in the use of diaries as an instrument for the reconfiguration of environmental teacher educators' reality. Therefore, diaries as a form of narrative should be reconsidered and articulated to the processes of permanent education in conversation meetings, which focus on the problems faced by teachers in the classroom, in particular the problems faced by teachers in their first years of teaching.

Keywords: Environmental Education. Teacher Education. Conversation Meetings.

\section{Introdução}

Este texto é resultado da dissertação de mestrado intitulada "Conversar para pertencer em rodas de formação: o processo de constituição de uma professora pesquisadora educadora ambiental na prática docente”. Nela adentramos no relato de constituição de uma professora principiante na prática docente em uma escola do campo de São José

\footnotetext{
* Mestre em Educação Ambiental, Universidade Federal do Rio Grande (FURG), Email: idaquimica@yahoo.com.br

* Master in Environmental Education, Federal University of Rio Grande (FURG), Email: idaquimica@yahoo.com.br

** Doutora em Educação, Universidade Federal do Rio Grande (FURG).

**Doctor in Education, Federal University of Rio Grande (FURG).
} 
do Norte. Ao mesmo tempo em que ingressa na docência, a professora inicia o mestrado e começa a sua caminhada como pesquisadora e educadora ambiental. Isso denota que a investigação trabalhou com a constituição da professora em três diferentes âmbitos: a pesquisa, a sala de aula e a educação ambiental como campo de conhecimento. Acredito que ela traz sua contribuição ao campo da Educação, uma vez que investiga os rituais de iniciação de uma professora.

Portanto, este artigo - no qual pretendo em um primeiro momento apresentar a pesquisa narrativa, suas características e possibilidades de uso na formação de professores - é um recorte da dissertação de mestrado. Além da narrativa, trago a possibilidade do uso do diário como ferramenta significativa no desenvolvimento de tais pesquisas, bem como o seu potencial para a compreensão do fazer docente. A partir disso, busco narrar um pouco da minha pesquisa de mestrado e dos resultados obtidos na escrita da mesma. Para potencializar tais processos, aposto nos processos coletivos e na sua recursividade como forma de compreensão de si por meio da mediação do outro.

\section{A pesquisa narrativa}

A pesquisa narrativa é um tipo de pesquisa que tem sua principal aplicação nas Ciências Sociais e na Saúde, e que encontra na área da Educação um campo fértil ao seu uso, representando uma nova forma de construção do conhecimento. Em um texto escrito por Galiazzi e Mello (2005), as autoras apresentam as principais características da pesquisa de Jean Clandinin e Michael Connelly, e afirmam que a vida pode ser entendida de forma narrativa. Sendo assim, a pesquisa pode ser compreendida como a própria narrativa da experiência vivida pelos seus participantes, na qual a história constitui o fenômeno a ser estudado e a narrativa é o método que a investiga e descreve.

Nesse tipo de pesquisa, a metodologia não objetiva chegar a resultados ou a verdades fixas, mas trazer à tona uma nova compreensão das realidades estudadas. No caso da pesquisa aqui apresentada, sua intencionalidade não foi a de julgar a prática docente e nem instituir verdades a respeito do início profissional de docentes, mas tentar compreender a experiência de começo de carreira e os processos envolvidos nessa etapa de constituição, de forma a poder contribuir para a formação de professores.

A pesquisa narrativa é também uma forma diferente de pesquisar, uma vez que tem objetivos diferentes de outros modos de fazer pesquisa qualitativa. E essa diferenciação torna-se evidente, quando Galiazzi e Melo dizem que:

Outra tensão aparece em relação aos objetivos da pesquisa. Na pesquisa formalista, o objetivo é contribuir para o desenvolvimento do paradigma teórico e da literatura associada. Um segundo objetivo pode ser replicar e aplicar a teoria do problema. Embora o primeiro objetivo possa também aparecer na pesquisa narrativa, o segundo raramente é contemplado. Dessa forma, os objetivos da pesquisa narrativa parecem criar mais espaço para construção de novos sentidos e significados com relação ao que está sendo pesquisado. (2005, p.6).

A respeito das diferenças entre as pesquisas formativa e narrativa, as autoras afirmam ainda:

Enquanto os pesquisadores formalistas começam a pesquisa pela teoria, os pesquisadores narrativos começam pela experiência. A pesquisa formalista com abordagens teóricas de autores reconhecidos 
como, por exemplo, Derrida, Foucault, Gadamer, Habermas, etc...A pesquisa narrativa começa com relatos de histórias de experiências vividas pelo pesquisador de forma a orientar ou expor narrativamente o foco do problema ou questão de pesquisa. Os pesquisadores formalistas geralmente querem que apareça um capítulo em separado, um capítulo sobre a estrutura da pesquisa, que identifique passos da literatura, que delineie principais linhas teóricas de pensamento e gere possibilidades potenciais de pesquisa. Os pesquisadores narrativos escrevem dissertações sem um capítulo de revisão de literatura específica. Eles articulam do início ao final uma tentativa de criar ligações entre a teoria e a prática, a experiência incorporada na pesquisa. (2005, p. 6).

Essa articulação feita pelos pesquisadores narrativos fica evidente na pesquisa ora apresentada, uma vez que os teóricos não foram buscados a priori para dialogar com o campo empírico. Foi somente com a análise mais aproximada dos dados empíricos e um mergulho mais profundo nas questões práticas registradas no diário que se delineou a busca por parceiros que fortalecessem os argumentos que a pesquisa permitia construir. Esse é um dos motivos que permite afirmar que a narrativa é o fenômeno estudado, configurando-se também como método de estudar esse fenômeno.

Em se tratando de narrativa de professores, esse tipo de pesquisa pode ser relevante em diferentes aspectos (lembrando que se trata de uma pesquisa narrativa): primeiro por se tratar de uma metodologia que permite que o docente reveja a sua prática e, a partir dessa revisão, a reflexão venha a ser favorecida, orientando assim as tomadas de decisão. Ou porque as narrativas possibilitam a compreensão dos professores como produtores de conhecimentos específicos do fazer docente. A esse respeito, Oliveira destaca:
Acreditamos no trabalho com narrativas docentes como forma de dar visibilidade às vozes, às práticas, aos significados dessas pessoas professoras e, neste sentido, nossas práticas de pesquisa nos levam não mais a descrever, denunciando as mazela e obstáculos das escolas e dos professores na realização de práticas emancipatórias e, nem mesmo em prescrições de como devem caminhar, mas no reconhecimento do outro enquanto produtor de conhecimento. (2006, p.173).

O uso de narrativa em investigação da prática docente faz com que o professor recupere seu papel em relação ao conhecimento pedagógico provindo da experiência em sala de aula, conhecimento esse que por vezes é esquecido ou mesmo menos valorizado, tornando-o o centro dos processos de formação inicial e permanente. Para argumentar em favor desta afirmativa, recorro a Dias:

$\mathrm{O}$ uso das narrativas tende a superar o modelo de formação, que reduz o docente à condição de audiência passiva, a mero executor de propostas idealizadas por outros - especialistas que se consideram detentores do saber - (re)colocando-os como participantes do processo de formação. Assim, recupera a autoria do trabalho do professor, valorizando a experiência do sujeito e seus elos culturais com mo coletivo. (2005, p.162).

Nesse sentido, o uso de narrativas de professores como material de pesquisa/ formação revela a possibilidade de compreensão do social de uma classe, de um grupo em especial e suas características enquanto grupo. Para Schwengber, a relevância desse tipo de trabalho é esta:

Trata-se de recuperar o professor enquanto sujeito histórico, fato esse que, até bem pouco tempo, era minimizado, a 
historicidade dos professores era tomada como um dado invisível, à medida que eles eram vistos como reprodutores de conhecimento, de ações e práticas que se efetivam através de outros agentes. (2004, p.235).

Como argumentado, a narrativa do professor pode ser utilizada como ferramenta de autoformação desse profissional. Como diz Oliveira: "Os professores [...] reorganizam, através do trabalho da memória, experiências, acontecimentos significativos na construção da suas performances, gerando um processo de autoformação”. (2004, p. 17). Nessa perspectiva, o professor que relata a sua prática de forma narrativa e depois a analisa tem possibilidade de reconstruir essa prática pedagógica, estando assim em constante processo de transformação.

A narrativa pode ser uma ferramenta não só de autoformação, mas também de formação para outros sujeitos do mesmo contexto, já que a experiência singular pode servir de exemplo a outras pessoas, pois apesar de as histórias não se repetirem, os contextos se ligam, compondo uma rede pela qual transitam significados. (WARSCHAUER, 2001).

E, por último, temos na pesquisa narrativa uma possibilidade de construção da identidade individual e coletiva, de entendimento do professor como sujeito histórico e que produz a história do profissional docente. Conforme as palavras de Oliveira:

Trata-se, primeiramente, de fazer o professor acreditar que é sujeito da história, e, principalmente neste caso, sujeito da história da profissão. Como uma memória subterrânea, como grupo sujeitado, o professor, ao relatar a sua história de vida, sistematiza acontecimentos significativos no seu processo de formação e subjetivação. Este trabalho de reconstrução de si mesmo e dos repertórios da profissão tende a definir o lugar social do professor e suas relações com os outros. (2004, p.21).

Optar por essa perspectiva metodológica como forma de compreensão da prática do professor é, por todos os motivos apresentados, uma importante contribuição para o campo da Educação, pois permite o entendimento dos rituais, hábitos e ritmos do professor e da sua vivência em sala de aula. A compreensão da experiência vivida permite que a partir do pretérito possa ser pensado e construído outro presente.

\section{Os diários do professor}

O diário apresenta-se, dentro das metodologias qualitativas, como um instrumento interessante de análise da prática e do pensamento do professor atuante em sala de aula. O diário permite mais do que explicar ações do professor; ele possibilita compreender processos de constituição desse profissional. Para Zabalza (2004), ao escrever o diário, o professor reconstrói a sua prática através da reflexão:

A redação dos diários leva consigo todo um conjunto de fases sucessivas que facilitam o estabelecimento de um processo de aprendizagem baseado em uma dupla categoria de fenômenos: (a) o processo de se tornar consciente da própria atuação ao ter de identificar seus componentes para narrá-los e (b) o processo de recodificar essa atuação (transformar a ação em texto), possibilita a racionalização das práticas e sua transformação em fenômenos modificáveis (e, portanto, possíveis de melhorar). (2004, p. 27).

No caso desta pesquisa, os diários foram escritos após cada aula dada, às vezes ainda na escola, quando havia algum tempo 
livre. Ao todo foram escritos sessenta e cinco relatos que procuravam narrar tudo que naquele momento parecia relevante, que de alguma forma havia causado perturbação na minha atuação dentro do contexto educacional. Como define Zabalza em seu livro sobre os diários de aula, “os diários de aula, pelo menos no que se refere ao sentido que recebem neste trabalho, são os documentos em que professores e professoras anotam suas impressões sobre o que vai acontecendo em suas aulas” (2004, p. 13). Com esses registros, podemos perceber as teorias pessoais que através da reflexão podem ser compreendidas e transformadas. A esse respeito concordo com Zabalza (2004), quando ele afirma:

Os professores serão melhores profissionais tanto quanto mais conscientes forem de suas práticas, quanto mais refletirem sobre suas intervenções. A reflexão sobre a própria prática, a introdução de proposições reflexivas na ação de ensinar faz com que saiamos de um terreno de certezas dadas por outros e de rotinas procedimentais, etc., para um terreno de tomada de decisões, de debate, de insegurança, de criação. (2004, p.23).

Dentro das possibilidades de uso do diário do professor como ferramenta de formação permanente dos profissionais da educação, é possível que o mesmo seja uma forma tanto de investigação da prática de sala de aula, quanto uma reflexão a respeito do fazer docente que possibilita novas intervenções nessa prática.

\section{As rodas como proposta de formação permanente}

Para a realização do estudo aqui abordado para a escrita da dissertação de mestrado, analisaram-se sessenta e cinco registros escritos no diário de campo sobre a sala de aula da professora, através da Análise Textual Discursiva (MORAES e GALIAZZI, 2007). Para a elaboração da análise, cada uma das escritas no diário foi considerada como uma unidade de sentido. Em um primeiro momento, essas unidades de sentido passaram por um processo de categorização; em seguida, as categorias foram organizadas por semelhanças. $\mathrm{Na}$ etapa seguinte, foram feitas a síntese e a reconstrução dos textos através de uma produção escrita, os metatextos.

Da análise acima indicada obteve-se a categoria intitulada "Conversas para lidar com os dilemas iniciais”, por meio da qual se teve a problematização e o aprofundamento teórico do que foi importante nesse primeiro ano de docência para a professora, pesquisadora e educadora ambiental. Essa categoria deu origem a cinco histórias que mostram as preocupações, as inseguranças, as satisfações, as alegrias e os dilemas da professora em seu início de carreira.

Partindo da análise da experiência da professora principiante na profissão, proponho uma maneira de se pensar a formação inicial e permanente de educadores considerando a articulação dessa formação com os princípios da Educação Ambiental. Para desencadear tal proposição, fez-se inicialmente uma discussão sobre o conceito de formação em Rodas, para depois se apresentar o conceito de pertencimento, sendo os dois conceitos fundamentais na realização dessa proposta.

Argumenta-se que a formação do professor iniciante pode ser intensificada em Rodas de formação, em rede de conversas sobre os dilemas enfrentados pelo professor iniciante. Uma da Rodas essenciais à promoção dessa formação seria realizada na escola, que é o lugar onde as teorias se concretizam. Em relação à Roda na escola, Warschauer ressalta: 
Trata-se, em suma, de não só reverter à concepção da formação segundo o modelo da racionalidade técnica que dicotomiza o lugar da formação e o lugar de sua aplicação, fazendo que a formação se dê num vazio, mas também propor dispositivos de formação contínua na escola, que é cenário de experiências dos professores, através da criação de oportunidades de reflexão sobre as experiências, da organização em colegiados, em redes de partilhas, em Rodas, transformando a estrutura organizacional, ao mesmo tempo que seus atores se (trans)formam, caracterizando assim uma organização que aprende e muda. (2001, p. 172).

Muitas vezes a organização do trabalho do professor nas escolas não facilita o convívio, pois os tempos e os espaços são diferenciados, o que não valoriza o convívio e a reflexão partilhada (WARSCHAUER, 2001). Porém, isso não pode ser obstáculo para que se promovam grupos de trocas, de conversas e de aprendizagens compartilhadas.

Marques também ressalta a relevância de os professores compartilharem seus saberes:

Daí a necessidade de se enfatizar o entendimento do cotidiano da escola como espaço formativo de construção/reconstrução do saber pedagógico de um docente que troca experiências e resgata histórias de vida na perspectiva de experiências e saberem compartilhados na interlocução e de ações em parceria. Formar em continuidade professores que aprendem das próprias experiências na interlocução de seus saberes práticos é formar professores-pesquisadores na busca de entenderem o que fazem como corpo docente, como comunidade de educadores. (2004, p. 85).

Os professores podem ainda interagir em diferentes Rodas, formando assim redes mais amplas de diálogo que podem integrar outros sujeitos como, por exemplo, interlocutores teóricos. Para defender essa afirmativa, trago as palavras de Warschauer:

Defender a formação dos professores através de redes de partilhas entre pares e na organização - escola não significa que se exclua da rede de conversas os especialistas e pesquisadores, pois seria prescindir de conhecimentos fundamentais que alimentam a prática docente. Entretanto, é necessário que o diálogo e a abertura para a aprendizagem entre estas categorias profissionais se dêem em reciprocidade e não reproduzindo a concepção de que os professores como práticos, devem aplicar as teorias geradas pelos especialistas do meio científico acadêmico. (2001, p. 183).

A inter-relação entre diferentes Rodas estabelece uma rede mais complexa de conversas e proporciona ainda mais aprendizagens com os diferentes atores, como nos diz Warschauer:

Se uma Roda já é uma rede de interações entre seus participantes, a inter-relação entre várias Rodas, pela existência de membros em comum, estabelece uma rede ainda mais complexa, cuja estrutura pode ser reorganizada constantemente porque está aberta a transformações, fruto das interações internas e externas. Essa rede não é uma estrutura cristalizada, mas representa um processo, uma jornada. Motivo pelo qual para falar dela é preciso contar sua história, narrar sua vida. (2001; p. 300).

Para que se concretizem as Rodas de formação é necessário que o professor tenha a percepção de pertencimento. E os resultados da pesquisa realizada permitem apostar em diferentes pertencimentos. Um deles é o de pertencer à profissão professor. A construção da identidade profissional é um processo lento e intenso de se entender 
professora, educadora e pesquisadora. Para isso é preciso pertencer à escola e à comunidade escolar e por ela se sentir e se fazer responsável.

Os registros da professora iniciante mostram que a inserção na sala de aula, as conversas com a direção, com os professores, com os alunos e pais foram mostrando à professora pesquisada as singularidades desse lugar de trabalho. Fez-se necessária a compreensão de pertencer à escola da qual fazia parte e entender um pouco mais sobre a escola na zona rural. E também argumento que pertencer à escola por si só não é suficiente. Amparo-me em Sá para a proposta de compreender o pertencimento como parte da identidade profissional do professor:

O princípio do pertencimento traz em seu bojo a questão da subjetividade como uma dimensão intrínseca do conhecimento vivo e humano, e que integrá-la é condição de acesso à objetividade, isto é, à possibilidade de um conhecimento que se sabe pertencente e se quer compatível com a complexidade do vivido. (2005, p. 252).

O fato de compreender-se fazendo parte de um lugar, valorizando-o, é fundamental para a nossa constituição como professores, conforme tão bem diz Arroyo:

Quando revisitamos nosso lugar, nossa cidade, matamos saudades e encontramos surpresas. Cada vizinho nos conta uma história do lugar. Não podemos acreditar em tudo, mas nos faz bem ouvi-las. Reacendem nossa memória e nossa identidade. Somos o lugar onde fizemos as pessoas com quem convivemos. Somos a história de que participamos. A memória coletiva que carregamos. (2002, p. 14).

Em se tratando ainda do pertencimento, faz-se necessária a compreensão de lugar e do que ele pode representar para os sujeitos. O lugar pode ser pensado, como diz Cousin (2004), como o contexto histórico e social em que estamos inseridos. Sobre a importância de conhecer o nosso lugar, a autora afirma:

Penso que, ao compreender o lugar em que vive o sujeito conhece a sua história e consegue entender as coisas que ali acontecem. Nenhum lugar é neutro. Pelo contrário, é repleto de história e com pessoas historicamente situadas num tempo e num espaço, o que pode ser um recorte de um espaço maior, mas por hipótese algum isolado, independente. (2004, p. 24).

Freire em sua obra também nos traz a noção de pertencimento, revelando que só é possível lutar pela mudança se compreendermos a nossa Terra como uma produção social e histórica, feita por homens e mulheres, como está explicito no seguinte parágrafo:

Por tudo isso, minha Terra envolve o meu sonho de liberdade. Que não posso impor a ninguém, mas porque sempre lutei. Pensar nela é assumir esse sonho que me alenta. É lutar por ele. Nunca pensei minha Terra de modo piegas: ela não é superior ou inferior a outras terras. A terra da gente é sua geografia, sua ecologia, sua topografia e biologia; mas também é o que mulheres e homens fazemos dela. Ela é como organizamos sua produção, fazemos sua História, sua educação, sua cultura, sua comida e ao gosto dela nos fixamos. A Terra da gente envolve luta por sonhos diferentes, às vezes antagônicos, como os de suas classes sociais. Minha Terra não é, afinal, uma abstração. (2006, p. 28).

Neste sentido, os processos de formação de professores precisam agregar o conceito de pertencimento do professor à escola, para dar coerência aos processos formativos. 


\section{Considerações finais}

Na dissertação de mestrado analisada buscou-se compreender os processos que constituíram a professora, pesquisadora e educadora ambiental em seu início de carreira. O diálogo aparece como um dos princípios fundamentais da prática docente que constituem essa professora. A experiência singular da narrativa de um sujeito, como é o caso da professora, possibilita conhecer e compreender processos que precisam ser problematizados na constituição de professores em início de carreira. O que se sugere, a partir da pesquisa realizada, é que essa problematização pode ser feita por meio de Rodas que discutam os dilemas da sala de aula. Além disso, propõe-se que o professor sinta-se pertencente à profissão docente e à comunidade escolar. E os processos em Rodas de formação favorecem esse sentir pertencendo-se.

Esta pesquisa está apoiada nos princípios da pesquisa qualitativa, da pesquisa narrativa e no uso do diário como ferramenta de registro do fazer docente. A análise dos dados nela obtidos seguiu os procedimentos da análise textual discursiva de Moraes e Galiazzi (2007), que consiste na unitarização, seguida de um processo de categorização das unidades obtidas e, por fim, da interpretação por meio da escrita de metatextos reflexivos sobre as unidades.

\section{Referências}

ARROYO, M. Ofício de mestre: imagens e auto-imagens. Petrópolis, RJ: Vozes, 2002.

COUSIN, C. S. Trilhas e itinerários da educação ambiental nos trabalhos de campo de uma comunidade de aprendizagem. Dissertação (Mestrado em Educação
Ambiental) - Fundação Universidade Federal do Rio Grande - FURG, Rio Grande. 2004. 143f.

DIAS, C. Possibilidades e limites no uso da abordagem (auto) biográfica da educação ambiental? In: GALIAZZI, M. C.; FREITAS, J. V. Metodologias emergentes em educação ambiental. Ijuí: Unijuí, 2005. FREIRE, P. Á sombra desta mangueira. São Paulo: Olho d’ Água, 2006.

FONTANA, R. C. Como nos tornamos professora? Belo Horizonte: Ed. Autêntica, 2005.

GALIAZZI, M. C.; MELLO, D. A paisagem da pesquisa narrativa. In: SEMINÁRIO DE PESQUISA QUALITATIVA, 4, 2005. Rio Grande. Oficinas... Rio Grande: FURG, 2005, p. 1-22.

MARQUES, M. O. Professores falantes de si na sala de aula, na escola e na constituição da Pedagogia. In: OLIVEIRA, Valeska (Org.). Imagens de professor. Ijuí: Unijuí, 2004.

MORAES, R.; GALIAZZI, M. C. Análise textual discursiva. Ijuí: Unijuí, 2007.

OLIVEIRA, V. F. Narrativas e saberes docentes. Ijuí: Unijuí, 2006.

SÁ, L. M. Pertencimento. In: Luis Antonio Ferraro Júnior (Org.). Encontros e caminhos: formação de educadoras (es) ambientais e coletivos educadores. Brasília: MMA, Diretoria de Educação Ambiental, 2005.

SCHWENGBER, M. S. V. As diferentes faces da escolha profissional. In: OLIVEIRA, Valeska (Org.). Imagens de professor. Ijuí: Unijuí, 2004.

WARSCHAUER, C. A roda e o registro: uma parceria entre professor, alunos e conhecimento. Rio de Janeiro: Paz e Terra, 1993. 
Rodas em rede: oportunidades formativas na escola e fora dela. Rio de Janeiro: Paz e Terra, 2001.

ZABALZA, M. A. Diários de aula: um instrumento de pesquisa e desenvolvimento profissional. Porto Alegre: Artmed, 2004.

Enviado em: 19/04/2010

Aceito em: 17/06/2011 